ORIGINAL RESEARCH PAPER

\title{
PHYSICAL PRE-TREATMENTS AS A TOOL FOR ENHANCING NUTRITIONAL FUNCTIONALITY OF GERMINATED LEGUMES
}

\author{
LIVIA PATRAȘCU1 ${ }^{1}$ INA VASILEAN² ${ }^{2}$ MARIA GARNAI², IULIANA APRODU ${ }^{2 *}$ \\ ${ }^{1}$ Cross-border Faculty, Dunarea de Jos University of Galati, 111 Domneasca Str, Galati, Romania \\ ${ }^{2}$ Faculty of Food Science and Engineering, Dunarea de Jos University of Galati, 111 Domneasca Str, Galati, \\ Romania \\ *corresponding author: iuliana.aprodu@ugal.ro
}

Received on 14 October 2020

Revised on 9 November 2020

\begin{abstract}
Physical treatments applied prior to germination were reported to influence the functionality of different seeds. The aim of the present study was to investigate the effect of pulsed light $\left(43.2 \mathrm{~J} / \mathrm{cm}^{2}\right)$, stationary magnetic field $(50 \mathrm{mT}, 1 \mathrm{~h})$, and ultrasounds $(130 \mathrm{~W} / 38 \mathrm{kHz}, 15 \mathrm{~min})$, pre-germination treatments on the functionality of different pulses, such as green lentils, chickpeas and broad beans. The ultrasounds and magnetic field pre-treated pulses exhibited similar antioxidant activity after germination, while pulsed light was the most efficient in increasing the content of total phenols. Regardless of the applied pre-treatment, chickpea germination resulted in increased vitamin B1 content. Although vitamin $\mathrm{C}$ was not quantified in raw seeds, important amounts were detected in germinated lentils and pulsed light treated broad beans. Protein digestibility was also influenced by the applied treatments before germination. The most advanced protein digestibility was registered for pulsed light treated samples. Overall, the pulsed light treatment was the most efficient in enhancing the nutritional functionality of legumes.
\end{abstract}

Keywords: germination, protein digestibility, antioxidant, thiamin, vitamin C

\section{Introduction}

It is known that germination improves the nutritional value of legumes by lowering the level of anti-nutritional components like lectins, phytic acid and trypsin inhibitors, and increasing the antioxidant activity. Many phenolic compounds, such as caffeic acid, ferulic acid, gallic acid, catechin and rutin, were found to increase with germination (Gan et al., 2016). Also, studies revealed that through de novo synthesis and transformations, germination can lead to vitamin accumulation in

https://doi.org/10.35219/foodtechnology.2020.2.08 
legume seeds, like vitamin C, the B group vitamins, or the E group vitamins (Gan et al., 2017 and cited literature therein).

In recent years, new technologies were adapted in order to improve the seeds' germination rate (Rifna et al., 2019). Different physical treatments like ultrasounds (Chiu and Sung, 2014), exposure to stationary magnetic field (Belyavskaya, 2004; Vashisth and Nagarajan, 2010; Shine et al., 2011), pulsed light (Vasilean et al., 2018a) or exposure to light of different wavelength (Vasilean et al., 2018b; Akgün et al., 2020), were reported to enhance the germination capacity of different seeds and legumes. The treatment based on the use of a static magnetic field of 7-200mT enhanced the germination efficiency of wheat and beans (Cakmak et al., 2010), soybeans (Shine et al., 2011) or alfalfa seeds (Hozayn et al., 2019), most probably due to the beneficial effect on $\alpha$-amylase activity, which was thought to improve germination (Afzal et al., 2012).

In addition to yield improvement, increased antioxidant activity in germinated legumes treated with pulsed light (Vasilean et al., 2018a) and light-emitting diode (LED) technology (Vasilean et al., 2018b) were reported. However, the information referring to the effect of different treatments applied to the seeds prior to germination on the bioactive compounds formation in seeds, in comparison to classic germination (involving seeds sanitization and soaking before germination), is still scarce. To the best of our knowledge there is no information regarding the effect of ultrasounds, or static magnetic field pre-treatment on bioactive compounds formation in germinated pulses.

The present study aimed to determine the possibility of improving the nutritional functionality of legumes by applying different physical treatments prior to germination. The synthesis of some compounds with antioxidant activity and the reduction of trypsin inhibitors in green lentil, broad bean and chickpea as the result of different physical treatments applied prior to germination were investigated and discussed.

\section{Materials and methods}

Three different pulses, namely green lentils, broad beans and chickpeas, were purchased from a local market (Galați, Romania).

\section{Physical pre-germination treatments}

After a preliminary soaking of 7 to $24 \mathrm{~h}$, depending on seed size, the pulses were subjected to three pre-germination treatments, namely pulsed light, ultrasounds, and static magnetic field.

For the first treatment the light pulses were generated by an IFP xenon type lamp with an electromagnetic field $(\lambda)$ of 200-1000 nm and impulse regime of $10^{-1}-10^{-4}$ s, as described by Turtoi and Nicolau (2007), applied at a fluence value of 43.2 $\mathrm{J} / \mathrm{m}^{2}$.

The ultrasounds treatment was performed on the soaked legume seeds placed in glass vessels, using an ultrasonic bath (Sonica 2200EP S3, Soltec Milano, Italy) at $39 \mathrm{kHz}, 310 \mathrm{~W}$ for 15 minutes. The temperature was maintained at $20^{\circ} \mathrm{C}$. 
The static magnetic field treatment was applied at $50 \mathrm{mT}$ for 1 hour to the soaked pulses placed in a cylindrical-shaped polypropylene holder. The required strength of the magnetic field was generated by means of magnets and measured by an Extech MF100 AC/DC Magnetic Field Meter (Extech Instruments).

\section{Legume germination}

Green lentils, broad beans and chickpeas were germinated under dark conditions for 12 to $72 \mathrm{~h}$, depending on seed size. Afterwards the germinated samples were dried at $55{ }^{\circ} \mathrm{C}$ for $24-30 \mathrm{~h}$ in a convection oven (LabTech LDO-030E, Daihan LabTech Co., LTD, Kyonggi-Do, Koreea). Before drying, the germinated broad bean and chickpeas were dehulled. The dried seeds were then ground using a laboratory mill (WZ-2, Sadkiewicz Instruments, Bydgoszcz, Poland) to obtain flours with particles size under $500 \mu \mathrm{m}$. The control samples were processed by the same steps (soaking, dehulling if necessary, and drying at $55^{\circ} \mathrm{C}$ ) before grinding.

\section{Chemical analyses}

Antioxidant activity

The antioxidant activity assessed as the ability to scavenge the free radicals of 2,2Diphenyl-1-picrylhydrazyl (DPPH) free radicals and the total phenolic compounds were determined by the methods described earlier by Patrascu et al. (2019) and expressed as IC50.

The total flavonoid content was determined using the colorimetric method presented by Chang et al. (2002) and expressed as mg quercetin/100 g flour.

\section{Vitamin BI and C}

VitaFast ${ }^{\circledR}$ Vitamin $C$ and VitaFast ${ }^{\circledR}$ Vitamin $B 1$ kits purchased from R-Biopharm (Darmstadt, Germany) were used to determine the contents of vitamins C and B1, respectively. The protocols indicated by the producer in the operation manual of VitaFast ${ }^{\circledR}$ kits were observed and the final evaluation of the data was performed using the RIDA ${ }^{\circledR}$ SOFT Win software of R-Biopharm.

\section{Protein hydrolysis degree}

The reduction of the trypsin inhibitors during the pulses' germination was estimated by means of the protein hydrolysis degree (DH\%). The DH\% was determined as described earlier by Patrascu et al. (2019), using the pH-STAT technique (Navarrete del Toro and García-Carreño, 2003; Spellman et al., 2003). The $\mathrm{DH} \%$ was reported as $\mathrm{g}$ hydrolysed protein/100 $\mathrm{g}$ total proteins.

\section{Statistical analysis}

The obtained results were statistically analysed using Microsoft Excel Software. The data were subjected to single factor ANOVA analysis, considering a significance level of $95.0 \%$. Fisher's least significant difference (LSD) test at 95.0\% confidence level used to determine differences between values was applied using the Statgraphics Centurion XVI.I (free trial) software. All analyses were carried out in duplicate and the data were reported as mean values \pm standard deviation. 


\section{Results and discussion}

The DPPH radical scavenging capacity was used to determine the effect of the physical treatments applied prior to germination on the antioxidant activity of the pulses studied. The DPPH method was reported to quantify the overall antioxidant capacity of a sample, without being specific to any particular antioxidant component (Shalaby and Shanab, 2013). Further determination of different compounds known to have high antioxidant activity, like phenols, flavonoids, vitamin $\mathrm{C}$ and vitamin $\mathrm{B} 1$ was used to identify any potential relation with the DPPH radical scavenging capacity.

The DPPH radical scavenging capacity was reported in Table 1 as IC50, representing the amount of legume flour required to scavenge $50 \%$ of DPPH under the assay conditions. It was observed that the germination process under dark conditions, without any pre-germination treatment, significantly increased the DPPH radical scavenging ability of the broad beans and chickpeas $(\mathrm{p}<0.05)$.

When comparing the effect of the physical pre-germination treatments on DPPH radical scavenging ability of the germinated pulses studied, it was observed that ultrasounds had a positive influence only in the case of germinated broad beans $(\mathrm{p}<0.05)$. As for the effect of the magnetic field pre-treatment, a significant improvement of the DPPH radical scavenging ability $(\mathrm{p}<0.05)$ was observed in the case of lentils and broad beans. In this respect, Balakhnina et al. (2015) reported that wheat seed treatment with the magnetic fields of $30 \mathrm{mT}$ resulted in an increase of plant antioxidant potential.

Table 1. The effect of physical treatments applied prior to germination on the DPPH scavenging capacity of lentils, broad beans, and chickpeas.

\begin{tabular}{lccc}
\hline \multirow{2}{*}{$\begin{array}{c}\text { Type of treatment prior } \\
\text { to germination }\end{array}$} & Lentils & IC50, mg \\
\cline { 2 - 4 } Control (raw sample) & $13.93 \pm 0.24^{\mathrm{a}, \mathrm{b}}$ & $33.88 \pm 2.12^{\mathrm{a}}$ & $28.15 \pm 1.50^{\mathrm{a}}$ \\
No treatment & $13.36 \pm 0.42^{\mathrm{b}, \mathrm{c}}$ & $24.56 \pm 1.73^{\mathrm{b}}$ & $23.39 \pm 1.01^{\mathrm{b}}$ \\
Ultrasounds & $14.50 \pm 0.18^{\mathrm{a}}$ & $7.16 \pm 0.17^{\mathrm{c}}$ & $28.06 \pm 0.32^{\mathrm{a}}$ \\
Magnetic field & $13.24 \pm 0.26^{\mathrm{c}}$ & $7.41 \pm 0.11^{\mathrm{c}}$ & $27.04 \pm 0.44^{\mathrm{a}}$ \\
Pulsed light & $12.07 \pm 0.05^{\mathrm{d}}$ & $5.91 \pm 0.07^{\mathrm{c}}$ & $20.13 \pm 0.28^{\mathrm{c}}$ \\
\hline
\end{tabular}

Means in a column that do not share a superscript letter are significantly different at $\mathrm{p}<0.05$

Among the three pre-germination treatments applied, pulsed light proved to be the most efficient in increasing the antioxidant activity of all three germinated legumes. The IC50 values of the pulsed light treated samples significantly decreased both in respect to the corresponding control $(\mathrm{p}<0.05)$, and to the germinated samples with no pre-treatment. The best results were obtained for broad beans treated under pulsed light, with an IC50 decrease of $82.5 \%$ as compared to the control sample. Moreover, among the three pulses studied, broad beans showed the highest improvement of DPPH radical scavenging ability after germination, for all the applied treatments. A significant decrease of IC50 values of lettuce leaves 
treated before germination under 0.85 and $3.42 \mathrm{~kJ} \cdot \mathrm{m}^{-2} \mathrm{UV}$ light was also reported by Ouhibi et al. (2014).

In addition to determining the antiradical scavenging capacity of germinated legumes, we also investigated the possible relations between IC50 results and the amount of specific compounds with known antioxidant effects. The antioxidant activity of vegetal materials is given to a large extent by non-enzymatic antioxidants like vitamins (vitamin $\mathrm{C}$, vitamin $\mathrm{B} 1$, vitamin $\mathrm{A}$, vitamin $\mathrm{D}$ and vitamin K), minerals, carotenoids, polyphenols and others (Gliszczynska-Swigło, and Oszmianski, 2013; Shalaby and Shanab, 2013).

The amounts of total phenols found in the investigated legumes germinated under different conditions are included in Table 2. When germination was conducted in the dark with no physical pre-treatment, the total phenolic content was significantly higher only the in case of broad beans $(\mathrm{p}<0.05)$. The ultrasounds treatment prior to germination had the opposite effect on the level of total phenolics in broad beans and chickpeas $(p<0.05)$, when compared to both control and germinated seeds with no pre-treatment, while the efficiency of the magnetic field treatment was noticed only in the case of the germinated broad beans as compared to the corresponding control.

Similar to the DPPH radical scavenging ability, the obtained results indicated that pulsed light treatment was efficient in increasing the content of total phenols in all the studied pulse samples in comparison to the corresponding controls $(\mathrm{p}<0.05)$. However, this preliminary treatment yielded the highest total phenolic contents only for germinated lentils and chickpeas. In the case of broad beans, the most efficient treatment was ultrasounds, which induced the increase of total phenolic content up to $302.8 \mathrm{mg} / 100 \mathrm{~g}$.

Table 2. The effect of physical treatments applied prior to germination on the total phenolic content of lentils, broad beans, and chickpeas.

\begin{tabular}{llll}
\hline \multirow{2}{*}{$\begin{array}{c}\text { Type of treatment prior to } \\
\text { germination }\end{array}$} & \multicolumn{2}{c}{ Total phenolic content, mg ferulic acid /100g } \\
\cline { 2 - 4 } & Lentils & Broad beans & Chickpeas \\
\hline Control (raw sample) & $125.35 \pm 0.36^{\mathrm{b}, \mathrm{c}}$ & $194.28 \pm 3.02^{\mathrm{c}}$ & $120.77 \pm 1.12^{\mathrm{b}}$ \\
No treatment & $125.23 \pm 0.93^{\mathrm{b}, \mathrm{c}}$ & $282.78 \pm 10.71^{\mathrm{b}}$ & $124.71 \pm 1.23^{\mathrm{b}}$ \\
Ultrasounds & $128.24 \pm 2.06^{\mathrm{b}}$ & $302.80 \pm 3.22^{\mathrm{a}}$ & $111.69 \pm 1.80^{\mathrm{c}}$ \\
Magnetic field & $122.97 \pm 2.29^{\mathrm{c}}$ & $270.65 \pm 1.44^{\mathrm{b}}$ & $121.42 \pm 2.28^{\mathrm{b}}$ \\
Pulsed light & $135.59 \pm 2.23^{\mathrm{a}}$ & $272.43 \pm 2.49^{\mathrm{b}}$ & $153.02 \pm 4.26^{\mathrm{a}}$ \\
\hline
\end{tabular}

Means in a column that do not share a superscript letter are significantly different at $\mathrm{p}<0.05$

A good linear correlation between the total phenolic content and DHHP radical scavenging activity was obtained in the case of chickpea, with $\mathrm{R}^{2}=0.8248$.

Flavonoids are synthesized in legumes mainly as a response to stress conditions, induced by the attacks of insects, microorganisms or even ultraviolet light (Beggs and Wellmann, 1994). Ouhibi et al. (2014) obtained a significant increase of the 
flavonoid content of lettuce leaves treated before germination under 0.85 and 3.42 $\mathrm{kJ} \cdot \mathrm{m}^{-2} \mathrm{UV}$ light. In the present study, only the pulsed light treatment determined a significant increase of the flavonoid content of all the studied legumes, when compared to the corresponding samples germinated with no physical pre-treatment (Table 3). Ultrasounds and the application of the $50 \mathrm{mT}$ magnetic field prior to germination lead to the significant increase of the flavonoid content only in the case of broad beans $(\mathrm{p}<0.05)$, with no influence on flavonoid formation in lentils and chickpeas ( $p>0.05$ ) in comparison to the corresponding control samples.

When considering the relationship between total flavonoid content and overall antioxidant activity expressed as DPPH radical scavenging ability, good linear correlations were obtained for broad beans and chickpeas; the $\mathrm{R}^{2}$ values were 0.8463 in the case of broad bean, and 0.9673 for chickpea flour.

Table 3. The effect of physical treatments applied prior to germination on the total flavonoid content of lentils, broad beans, and chickpeas.

\begin{tabular}{llll}
\hline \multirow{2}{*}{$\begin{array}{c}\text { Type of treatment prior to } \\
\text { germination }\end{array}$} & \multicolumn{3}{c}{ Total flavonoid content, mg quercetin $/ \mathbf{1 0 0 g}$} \\
\cline { 2 - 4 } & Lentils & Broad beans & Chickpeas \\
\hline Control (raw sample) & $28.53 \pm 1.74^{\mathrm{b}}$ & $23.61 \pm 0.35^{\mathrm{d}}$ & $64.03 \pm 2.85^{\mathrm{b}, \mathrm{c}}$ \\
No treatment & $28.42 \pm 0.35^{\mathrm{b}}$ & $35.06 \pm 2.44^{\mathrm{c}}$ & $74.93 \pm 8.27^{\mathrm{b}}$ \\
Ultrasounds & $30.31 \pm 0.70^{\mathrm{a}, \mathrm{b}}$ & $37.59 \pm 0.04^{\mathrm{b}, \mathrm{c}}$ & $60.92 \pm 3.34^{\mathrm{c}}$ \\
Magnetic field & $30.50 \pm 1.74^{\mathrm{a}, \mathrm{b}}$ & $39.27 \pm 0.35^{\mathrm{a}, \mathrm{b}}$ & $67.00 \pm 0.36^{\mathrm{b}, \mathrm{c}}$ \\
Pulsed light & $33.43 \pm 1.38^{\mathrm{a}}$ & $42.05 \pm 0.32^{\mathrm{a}}$ & $90.03 \pm 4.98^{\mathrm{a}}$ \\
\hline
\end{tabular}

Means in a column that do not share a superscript letter are significantly different at $\mathrm{p}<0.05$

The presence of vitamin B1 was determined in all the studied legumes. Analysing the results shown in Table 4, it can be observed that the germination process itself (samples germinated under dark, with no applied pre-treatment) led to the significant increase of the thiamine content of lentils and chickpeas. On the other hand, in the case of broad beans, among all the types of physical treatments applied prior to germination, only the magnetic field allowed the significant increase of the content of vitamin B1 in the germinated sample as compared to the control $(\mathrm{p}<0.05)$. A good linear correlation between the content of vitamin B1 and IC50 value was obtained for the lentil samples $\left(\mathrm{R}^{2}\right.$ of 0.8975$)$. Similar to our findings, Aslam et al. (2008) reported negligible amounts of $\mathrm{B}_{1}$ vitamin in germinated chickpea seeds $(0.05-0.015 \mu \mathrm{g} / \mathrm{g})$.

The presence of vitamin $\mathrm{C}$ was not detected in raw lentil and broad bean samples. Except for the magnetic field treated sample, lentil germination resulted in synthesis of vitamin $\mathrm{C}$ up to contents of $18.48 \mathrm{mg} / 100 \mathrm{~g}$. In the case of broad beans, the presence of vitamin $\mathrm{C}$ could be detected only in the sample pre-treated through pulsed light prior to germination (Table 4). Finally, regardless of the applied pretreatment, germination resulted in no influence on the vitamin $\mathrm{C}$ content of the chickpea samples ( $>>0.05)$. In this respect, Doblado et al. (2007) found vitamin C 
formation in germinated chickpeas treated under high pressure, with values ranging between 14.9 and $25.2 \mathrm{mg} / 100 \mathrm{~g}$, depending on treatment and germination time. An important increase of the vitamin $\mathrm{C}$ level during lupin germination was observed by Frias et al. (2005), who reported levels of $6.48 \mathrm{mg}$ vitamin C/100g in raw lupin seeds and up to $56 \mathrm{mg}$ vitamin $\mathrm{C} / 100 \mathrm{~g}$ after nine days of germination.

No correlation could be established between the content of vitamin $\mathrm{C}$ and the antioxidant activity of the investigated pulses.

Table 4. The effect of physical treatments applied prior to germination on the synthesis of vitamins $\mathrm{B} 1$ and $\mathrm{C}$ in lentils, broad beans and chickpeas.

\begin{tabular}{llcc}
\hline \multirow{2}{*}{$\begin{array}{c}\text { Type of treatment prior to } \\
\text { germination }\end{array}$} & Lentils & \multicolumn{1}{c}{ Broad beans } & Chickpeas \\
\cline { 2 - 4 } & \multicolumn{3}{c}{ Vitamin B1, mg/100g } \\
\hline Control (raw sample) & $3.77 \pm 0.01^{\mathrm{d}}$ & $3.82 \pm 0.14^{\mathrm{b}}$ & $3.69 \pm 0.14^{\mathrm{b}}$ \\
No treatment & $4.38 \pm 0.25^{\mathrm{b}}$ & $3.52 \pm 0.07^{\mathrm{c}}$ & $4.64 \pm 0.13^{\mathrm{a}}$ \\
Ultrasounds & $3.85 \pm 0.25^{\mathrm{c}, \mathrm{d}}$ & $3.93 \pm 0.08^{\mathrm{a}, \mathrm{b}}$ & $4.57 \pm 0.00^{\mathrm{a}}$ \\
Magnetic field & $4.24 \pm 0.10^{\mathrm{b}, \mathrm{c}}$ & $4.11 \pm 0.05^{\mathrm{a}}$ & $4.04 \pm 0.12^{\mathrm{b}}$ \\
Pulsed light & $4.91 \pm 0.16^{\mathrm{a}}$ & $3.79 \pm 0.17^{\mathrm{b}, \mathrm{c}}$ & $5.07 \pm 0.39^{\mathrm{a}}$ \\
\hline \multicolumn{3}{c}{ Vitamin C, $\mathbf{~ m g / 1 0 0 g}$} \\
\hline Control (raw sample) & $\mathrm{ND}^{*}$ & $\mathrm{ND}$ & $18.49 \pm 0.01^{\mathrm{a}}$ \\
No treatment & $18.45 \pm 0.00^{\mathrm{b}}$ & $\mathrm{ND}$ & $18.46 \pm 0.00^{\mathrm{b}}$ \\
Ultrasounds & $18.48 \pm 0.00^{\mathrm{a}}$ & $\mathrm{ND}$ & $18.46 \pm 0.01^{\mathrm{b}}$ \\
Magnetic field & $\mathrm{ND}$ & $\mathrm{ND}$ & $18.44 \pm 0.01^{\mathrm{b}}$ \\
Pulsed light & $18.43 \pm 0.00^{\mathrm{c}}$ & $18.47 \pm 0.01$ & $18.44 \pm 0.00^{\mathrm{b}}$ \\
\hline
\end{tabular}

Means in a column that do not share a superscript letter are significantly different at $\mathrm{p}<0.05$; ${ }^{*} \mathrm{ND}-$ not detected

Protein digestibility and the biological value of legume proteins are highly influenced by the presence and activity of trypsin inhibitors. In order to highlight the presence of trypsin inhibitors in the germinated legumes, and also to emphasize the effect of some physical pre-germination treatments on their level and activity, the cleavage performance of trypsin was determined, and the results were included in Figure 1. The efficiency of the germination process in reducing the trypsin inhibitors from legume seeds was previously reported by Aguilera et al. (2013) and Chandrashekharaiah (2013). The ability of trypsin to recognize and specifically cleave the peptide bonds within proteins varied according to the legume type. The highest degree of hydrolysis (DH\%) was obtained in the case of chickpeas, for both raw and germinated seeds. The pulsed light pre-treatment resulted in a significant increase of $\mathrm{DH} \%$ for all the legumes studied. On the other hand, all the magnetic field and ultrasounds pre-treated samples presented significantly lower $\mathrm{DH} \%$ values in comparison to the corresponding samples germinated with no prior physical treatment $(\mathrm{p}<0.05)$. These results might be due to the synthesis of higher levels of trypsin inhibitors, or to the changes induced in the three-dimensional 
structure of proteins which might prevent the efficient recognition of different peptide bonds by the enzyme.

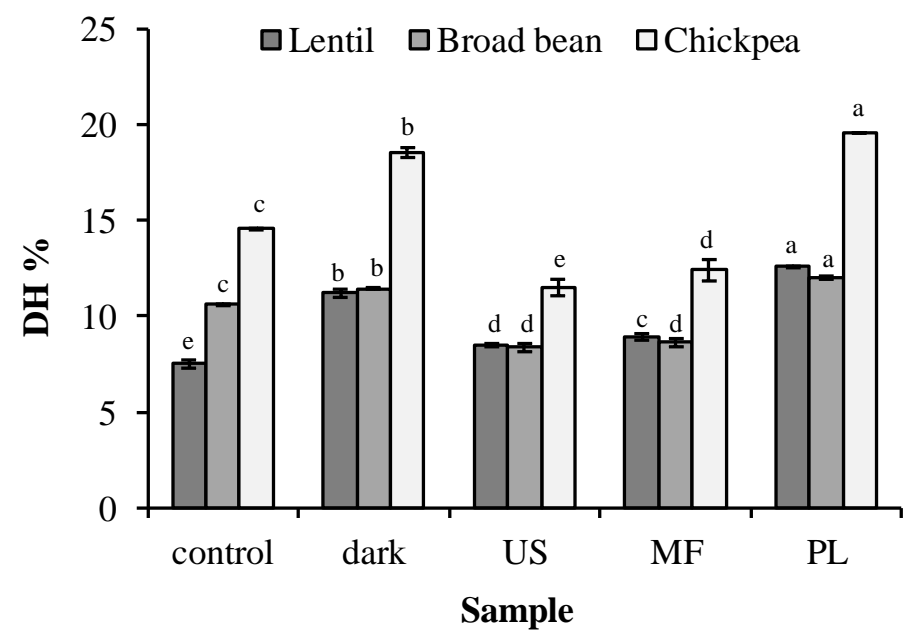

Figure 1. The influence of physical treatments applied prior to germination on the digestibility of protein from lentils, broad beans and chickpeas. Mean values of the same type of legume that do not share a letter are significantly different at $\mathrm{p}<0.05$.

\section{Conclusions}

Green lentils, broad beans and chickpeas, were subjected to germination after applying different preliminary physical treatments through pulsed light, magnetic field or ultrasounds. Generally, the results indicated that the application of physical treatments prior to germination can be used to improve the level of biologically active compounds in both small and big seed legumes. Out of the three pregermination treatments considered in the study, pulsed light appeared to be the most effective in enhancing the antioxidant activity, as well as the protein digestibility of the legumes under study. Although ultrasounds and magnetic field improved the antioxidant activity of the germinated samples, a negative effect on protein digestibility was observed in all the pulses investigated .

Acknowledgments: This work was supported by a grant of the Romanian National Authority for Scientific Research and Innovation, CNCS/CCCDI-UEFISCDI, project PN-III-P2-2.1-PED-2016-0155, within PNCDI III. The Research and Development Center for Thermoset Matrix Composites is also acknowledged for providing technical support.

\section{References}

Afzal, I., Mukhtar, K., Qasim, M., Basra, S. M. A., Shahid, M., Haq, Z. 2012. Magnetic stimulation of marigold seed. International Agrophysics, 26(4), 335. 
Aguilera, Y., Díaz, M. F., Jiménez, T., Benítez, V., Herrera, T., Cuadrado, C., MartínPedrosa, M., Martín-Cabrejas, M. A. 2013. Changes in non-nutritional factors and antioxidant activity during germination of nonconventional legumes. Journal of Agricultural and Food Chemistry, 61(34), 8120-8125.

Akgün, M., Akgün, M., Özcan, M. M., Şenyurt, Ö., Korkmaz, K. 2020. Effect of Led Light on Seed Germation of Basil. Ordu University Journal of Science and Technology, 10(1), 57-65.

Balakhnina, T., Bulak, P., Nosalewicz, M., Pietruszewski, S., Włodarczyk, T. (2015). The influence of wheat Triticum aestivum L. seed pre-sowing treatment with magnetic fields on germination, seedling growth, and antioxidant potential under optimal soil watering and flooding. Acta physiologiae plantarum, 37(3), 59.

Beggs, C. J. and Wellmann, E. 1994. Photocontrol of flavonoid biosynthesis. In Photomorphogenesis in Plants (pp. 733-751). Springer, Dordrecht.

Belyavskaya, N. A. 2004. Biological effects due to weak magnetic field on plants. Advances in Space Research, 34(7), 1566-1574.

Cakmak, T., Dumlupinar, R., Erdal, S. 2010. Acceleration of germination and early growth of wheat and bean seedlings grown under various magnetic field and osmotic conditions. Bioelectromagnetics, 31(2), 120-129.

Chandrashekharaiah, K. S. 2013. Storage proteins and trypsin inhibitors of an underutilized Legume, Mucuna: variability and their stability during germination. American Journal of Plant Sciences, 4(4), 910-916.

Chang, C. C., Yang, M. H., Wen, H. M., Chern, J. C. 2002. Estimation of total flavonoid content in propolis by two complementary colorimetric methods. Journal of Food and Drug Analysis, 10(3), 178-182.

Chiu, K. Y., Sung, J. M. 2014. Use of ultrasonication to enhance pea seed germination and microbial quality of pea sprouts. International Journal of Food Science \& Technology, 49(7), 1699-1706.

Doblado, R., Frías, J., Vidal-Valverde, C. 2007. Changes in vitamin C content and antioxidant capacity of raw and germinated cowpea (Vigna sinensis var. carilla) seeds induced by high pressure treatment. Food Chemistry, 101(3), 918-923.

Frias, J., Miranda, M. L., Doblado, R., Vidal-Valverde, C. 2005. Effect of germination and fermentation on the antioxidant vitamin content and antioxidant capacity of Lupinus albus L. var. Multolupa. Food Chemistry, 92(2), 211-220.

Gan, R. Y., Lui, W. Y., Wu, K., Chan, C. L., Dai, S. H., Sui, Z. Q., Corke, H. 2017. Bioactive compounds and bioactivities of germinated edible seeds and sprouts: An updated review. Trends in Food Science \& Technology, 59, 1-14.

Gan, R. Y., Wang, M. F., Lui, W. Y., Wu, K., Corke, H. 2016. Dynamic changes in phytochemical composition and antioxidant capacity in green and black mung bean (Vigna radiata) sprouts. International Journal of Food Science \& Technology, 51(9), 2090-2098.

Gliszczynska-Swigło, A., Oszmianski, J. 2013. Antioxidant and Prooxidant Activity of Food Components. In Food Oxidants and Antioxidants: Chemical, Biological, and Functional Properties, 375.

Hozayn, M., Ahmed, A. A., El-Saady, A. A., Abd-Elmonem, A. A. 2019. Enhancement in germination, seedling attributes and yields of alfalfa (Medicago sativa, L.) under 
salinity stress using static magnetic field treatments. Eurasian Journal of Biosciences, 13(1), 369-378.

Navarrete del Toro, M. A. and García-Carreño, F. L. 2003. Evaluation of the progress of protein hydrolysis. Current Protocols in Food Analytical Chemistry, 10(1), B2-2.

Ouhibi, C., Attia, H., Rebah, F., Msilini, N., Chebbi, M., Aarrouf, J., ... Lachaal, M. 2014. Salt stress mitigation by seed priming with UV-C in lettuce plants: Growth, antioxidant activity and phenolic compounds. Plant Physiology and Biochemistry, 83, 126-133.

Patrascu, L., Vasilean, I., Turtoi, M., Garnai, M., Aprodu, I. 2019. Pulse germination as tool for modulating their functionality in wheat flour sourdoughs. Quality Assurance and Safety of Crops \& Foods, 11(3), 269-282.

Rifna, E. J., Ramanan, K. R., Mahendran, R. (2019). Emerging technology applications for improving seed germination. Trends in Food Science \& Technology, 86, 95-108.

Shalaby, E. A. and Shanab, S. M. 2013. Antioxidant compounds, assays of determination and mode of action. African Journal of Pharmacy and Pharmacology, 7(10), 528-539.

Shine, M. B., Guruprasad, K. N., Anand, A. 2011. Enhancement of germination, growth, and photosynthesis in soybean by pre-treatment of seeds with magnetic field. Bioelectromagnetics, 32(6), 474-484.

Spellman, D., McEvoy, E., O'cuinn, G., FitzGerald, R. J. 2003. Proteinase and exopeptidase hydrolysis of whey protein: Comparison of the TNBS, OPA and pH stat methods for quantification of degree of hydrolysis. International dairy journal, 13(6), 447-453.

Turtoi M. and Nicolau A. 2007. Intense light pulse treatment as alternative method for mould spores destruction on paper-polyethylene packaging material. Journal of Food Engineering, 83(1), 47-53.

Vashisth, A. and Nagarajan, S. 2010. Effect on germination and early growth characteristics in sunflower (Helianthus annuus) seeds exposed to static magnetic field. Journal of Plant Physiology, 167(2), 149-156.

Vasilean, I., Aprodu, I., Neculau, M., Patrascu, L. 2018a. Effects of pulsed light treatment on germination efficiency of pulses. Scientific Papers: Series D, Animal Science-The International Session of Scientific Communications of the Faculty of Animal Science, 61, 266-274.

Vasilean, I., Cîrciumaru, A., Garnai, M., Patrascu, L. 2018b. The influence of light wavelength on the germination performance of legumes. The Annals of the University Dunarea de Jos of Galati. Fascicle VI-Food Technology, 42(2), 95-108. 